\title{
Monitoring and forecasting analysis of a landslide in Xinmo, Mao County, using Sentinel-1 data
}

\author{
Yuxin $\mathrm{Liu}^{1}$, Caijun $\mathrm{Xu}^{1,2,3, *}$, and Yang $\mathrm{Liu}^{1,2,3}$ \\ ${ }^{1}$ School of Geodesy and Geomatics, Wuhan University, Wuhan, China \\ ${ }^{2}$ Key Laboratory of Geo-space Environment and Geodesy, Ministry of Education, Wuhan University, Wuhan, China \\ ${ }^{3}$ Collaborative Innovation Center of Geospatial Technology, Wuhan University, Wuhan, China
}

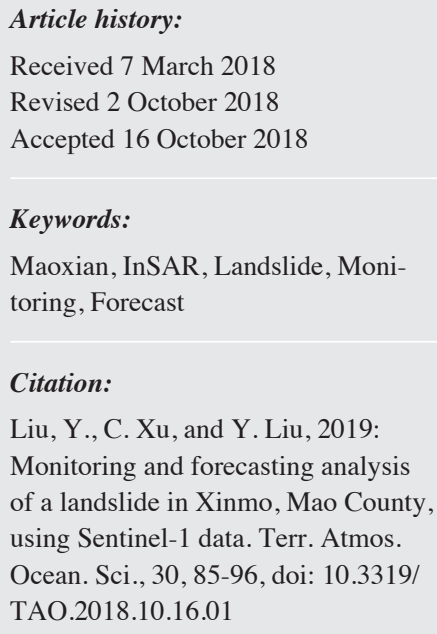

Received 7 March 2018

Revised 2 October 2018

Accepted 16 October 2018

Keywords:

Maoxian, InSAR, Landslide, Monitoring, Forecast

Citation:

Liu, Y., C. Xu, and Y. Liu, 2019: Monitoring and forecasting analysis of a landslide in Xinmo, Mao County, using Sentinel-1 data. Terr. Atmos. Ocean. Sci., 30, 85-96, doi: 10.3319/ TAO.2018.10.16.01

\begin{abstract}
On 24 June 2017, an enormous landslide struck the village of Xinmo in Mao County, Sichuan Province. Synthetic aperture radar (SAR) images from the Sentinel-1 satellite are chosen to monitor the landslide using the small baseline set (SBAS) technology, following which the deformation time series are obtained for the source area and are found to be consistent with the accelerated creep model. The displacement time series before the landslide clearly show movement processes associated with transient creep, steady-state creep and tertiary creep. The main deformation area is ascertained by calculating the average displacement of 5 representative regions. Three-month time series before the landslide are selected to calculate the failure time of the landslide both separately and together using the inverse-velocity method. The results show that the time series of the main deformation area can fit a linear model of the inverse velocities better than those of the marginal area, and the forecasted time is closer to the actual failure time. The forecasted time calculated using the time series of three regions in main deformation area is June 25 , which is only one day apart from the actual failure time.
\end{abstract}

\section{INTRODUCTION}

Landslides are common geological disasters in mountainous areas subjected to the influences of tectonic activities (Huang 2007). There are many such mountainous areas throughout the western regions of China, which frequently experiences seismic activity and is consequently host to a wide distribution of landslides, which are more likely to occur during the rainy season (Guidicini and Iwasa 1997). Landslides pose an enormous threat to the lives and property of local residents. The bursting characteristics of landslides are one of the primary reasons that they cause such enormous losses, and thus, landslide monitoring and forecasting are very important. Professional and accurate observation and monitoring methods are the foundation of landslide prediction and forecasting endeavors. In addition to traditional sensors, highly precise large-scale earth observation systems such as global positioning system (GPS) services and interferometric synthetic aperture radar (InSAR), both of which provide data with greater reliability for landslide research,

\footnotetext{
* Corresponding author

E-mail:cjxu@sgg.whu.edu.cn
}

have been developed in recent years. With the temporal and spatial evolution of SAR image time series detection and the corresponding development of InSAR technology, the permanent scatter (PS) and small baseline set (SBAS) technologies have shown good potential for landslide monitoring (Ferretti et al. 1999; Berardino et al. 2002; Liao et al. 2012; Tizzani et al. 2013). Time series InSAR analysis exhibits a bright future as a new type of slow ground deformation monitoring technology.

The village of Xinmo is located on the eastern bank of the Minjiang River in northwestern Mao County, Sichuan Province. On the southern side of the area is the NE-trending Longmen Shan fault zone, and the NS-trending Huya fault zone is situated along the northern side. The Xinmo landslide zone is located at the intersection of the NS-trending Minjiang fault zone and the NW-trending Songpinggou fault zone. The geological structure in this area is unstable and prone to geological disasters. Frequent earthquakes strike the landslide area, including three major earthquakes: the Diexi earthquake in $1933(\mathrm{M}=7.5)$, the SongpanPingwu earthquake in $1976(\mathrm{M}=7.2)$, and the Wenchuan 
earthquake in $2008(\mathrm{M}=8.0)$. The epicenter of the Diexi earthquake, following which several barriers formed in the Minjiang River, was only a few kilometers away from the landslide area (Fig. 1). The Wenchuan earthquake caused 15000 incidences of geohazards in the form of rockfalls, debris flows, and other types of landslides that caused approximately 20000 fatalities, and more than 10000 additional potential geohazard sites were induced by the earthquake (Yin et al. 2009; Shao et al. 2017).

The source area of the Xinmo village landslide is located at $103^{\circ} 39^{\prime} 46^{\prime \prime} \mathrm{E}, 32^{\circ} 4{ }^{\prime} 47^{\prime \prime} \mathrm{N}$. The collapse area is approximately $200 \mathrm{~m}$ long and $300 \mathrm{~m}$ wide with an average thickness of approximately $70 \mathrm{~m}$, and the volume of the collapse area is approximately $450 \times 104 \mathrm{~m}^{3}$ (Shao et al. 2017). The rock mass slid out along a rock layer, after which the landslide body fell rapidly and moved at a high speed along the slope, scraping an accumulation of debris from the slope face and increasing the volume of the body. After advancing to the location of the original fan-shaped, old landslide stack at the foot of the slope, the moving block spread out to either side and continued moving until it reached the bottom of the valley, at which point it was blocked by the mountain on the opposite side. Ultimately, the mass covered a distance of more than $2600 \mathrm{~m}$ over a relief of almost $1200 \mathrm{~m}$, and it formed an accumulated body with a length of $500 \mathrm{~m}$, a thickness of $10 \mathrm{~m}$, and a width of approximately $1200 \mathrm{~m}$ along the river (Fan et al. 2017). The main research focus of this paper is the collapsed area in the upper part of the landslide region (Fig. 2).

The landslide developed along the top of a sharp ridgeline that was easily broken under the influence of a strong earthquake due to seismic wave amplification effects (Xu et al. 2017). The landslide occurred within the Zagunao Formation $\left(\mathrm{T}_{2 \mathrm{z}}\right)$, which is mainly composed of metamorphic sandstone and slate and is characterized by a relatively low mechanical strength and well-developed weak structural planes. The orientation and dip angle of the bedding planes are practically coincident with those of the hillslope, which greatly facilitates basal sliding. A system of crack formed during the 1933 Diexi earthquake constitute a preferential flow path for the infiltration of rainwater, which could accelerate the physico-chemical weathering of the relatively weak rocks of the Zagunao Formation. Long-term gravity effects further induced the propagation of cracks, eventually causing the source rock material to enter a state of incipient instability. The consequence of rain falling over a long duration eventually destroyed the state and triggered the landslide (Fan et al. 2017; Xu et al. 2017).

Sentinel-1 satellite data were selected for this paper because they are characterized by a short revisit period, a large coverage area and a convenient data acquisition scheme. We collected descending-track satellite images before the landslide from 9 November 2016 to 19 June 2017. The data were then processed using the SBAS method to obtain time series of the deformation before the event. Furthermore, the trend of the displacement in certain regions was further analyzed.

\section{PROCESSING OF INSAR DATA}

The magnitude of the displacement before a landslide is small and unstable, and a landslide event usually occurs suddenly with a high uncertainty (Zeng 2009). Therefore, it is necessary to select short-wavelength SAR images with short revisit periods. This experiment used SAR imagery acquired by the Sentinel-1 satellite in interferometric wide (IW) swath mode from 9 November 2016 to 19 June 2017, the relative orbit number is 62 , and frame is 482 and 487 , over a time span of 222 days for a total of 15 descendingtrack images (Table 1). A digital elevation model (DEM) with a resolution of $30 \mathrm{~m}$ provided by the Shuttle Radar Topography Mission (SRTM) was used for differential InSAR (DInSAR).

To obtain the time series of the landslide displacement, the SBAS method was employed in this paper while considering the dense vegetation around the landslide area and the difficulty involved in obtaining PS points. This method divides all SAR images into different short baseline subsets according to spatial and temporal baselines Images in each subset are processed by differential interferometry respectively to improve coherence and increase the number of differential interferograms under the condition of single master image. Singular value decomposition (SVD) method is used to suppress the effect of DEM error and atmospheric phase delay on the deformation signal by connecting each differential interferogram based on the relationship between the coherent pixels and observation time. Then the minimumnorm least-square solution of surface deformation rate is obtained (Berardino et al. 2002).

In addition, 10:2 multi-look processing was performed on all of the images to suppress noise and maintain a certain degree of coherence. The time baseline was set to 90 days and the spatial baseline was set to $\pm 150 \mathrm{~m}$ to automatically select the interferograms for DInSAR processing, which included registration, interference, differential and phase unwrapping and geocoding. Since the monitoring area is located in a mountainous region, there are difficulties associated with time decoherence; moreover, the results of unwrapping contain a certain degree of error. Therefore, the phase-unwrapping results were checked and corrected by a phase-closure method (Biggs et al. 2007). According to the unwrapping results, we selected the interferograms with a high coherence for the follow-up calculations. The results of this selection are shown in Fig. 3 with a temporal baseline of up to 90 days and a spatial baseline of up to $142 \mathrm{~m}$; a total of 32 interferograms were chosen (Table 2). Then, the SBAS method was used to extract the time series of each point before the landslide. 
된
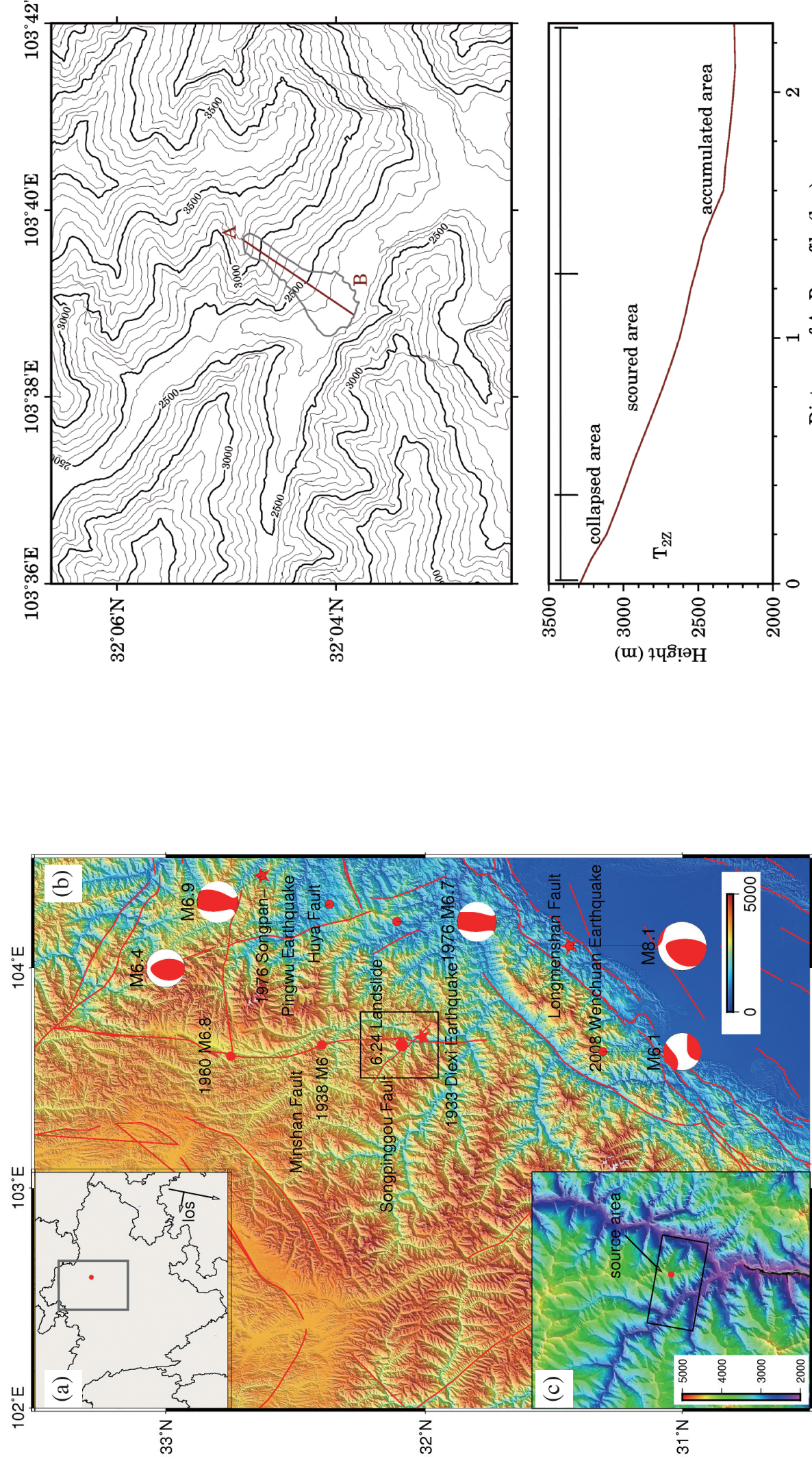

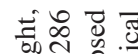

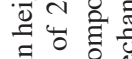

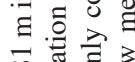

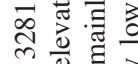

要

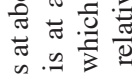

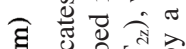

응

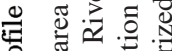

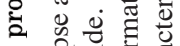

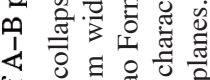

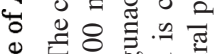

Ð

要专焉

a 吾 on 흐을 을

월

들

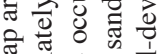

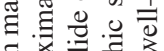

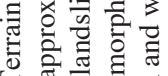
ㄴ. on

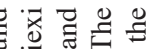

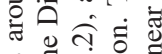

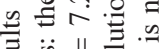

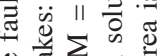

의

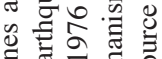

国

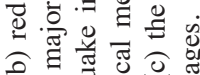

仓ิ

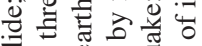

氜导焉

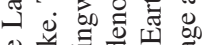

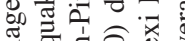

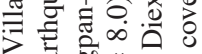

ฮึ

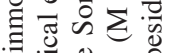

政

on

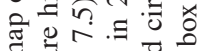

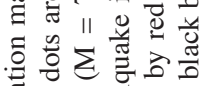

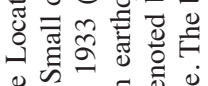

की

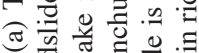

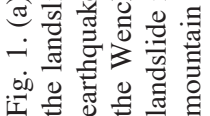


Table 1. Details of Sentinel-1 images used in this study.

\begin{tabular}{c|c|c|c|c|c|c|c|c}
\hline ID & Satellite & Path & Frame & Date & Inc $\left(^{\circ}\right)$ & Azi. $\left(^{\circ}\right)$ & $\begin{array}{c}\text { Maximum time } \\
\text { baseline setting (d) }\end{array}$ & $\begin{array}{c}\text { Maximum spatial } \\
\text { baseline setting (m) }\end{array}$ \\
\hline 1 & Sentinel-1B & 62 & 483 & $11 / 9 / 16$ & 33.9 & -167.2 & & \\
2 & Sentinel-1B & 62 & 483 & $12 / 3 / 16$ & 33.9 & -167.2 & & \\
3 & Sentinel-1B & 62 & 483 & $12 / 27 / 16$ & 33.9 & -167.2 & & \\
4 & Sentinel-1B & 62 & 483 & $1 / 20 / 17$ & 33.9 & -167.3 & & \\
5 & Sentinel-1B & 62 & 483 & $2 / 13 / 17$ & 33.9 & -167.2 & & \\
6 & Sentinel-1A & 62 & 483 & $2 / 19 / 17$ & 33.9 & -167.2 & & \\
7 & Sentinel-1A & 62 & 483 & $3 / 3 / 17$ & 33.9 & -167.2 & & \\
8 & Sentinel-1A & 62 & 487 & $3 / 15 / 17$ & 33.9 & -167.2 & & \\
9 & Sentinel-1A & 62 & 487 & $3 / 27 / 17$ & 33.9 & -167.2 & & \\
10 & Sentinel-1A & 62 & 487 & $4 / 8 / 17$ & 33.9 & -167.2 & & \\
11 & Sentinel-1A & 62 & 487 & $5 / 2 / 17$ & 33.9 & -167.2 & & \\
12 & Sentinel-1A & 62 & 487 & $5 / 14 / 17$ & 33.9 & -167.2 & & \\
13 & Sentinel-1A & 62 & 487 & $5 / 26 / 17$ & 33.9 & -167.2 & & \\
14 & Sentinel-1A & 62 & 487 & $6 / 7 / 17$ & 33.9 & -167.2 & & \\
15 & Sentinel-1A & 62 & 487 & $6 / 19 / 17$ & 33.9 & -167.2 & & \\
\hline
\end{tabular}

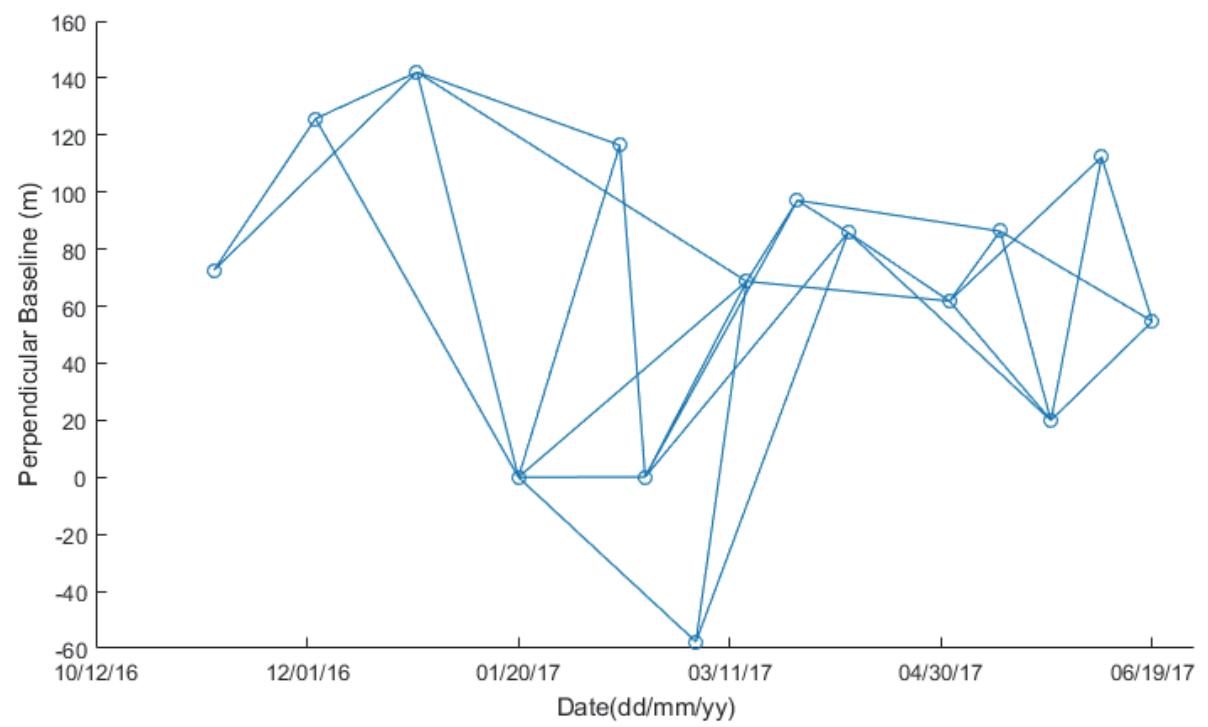

Fig. 3. Interferometric combinations of images. The baseline time was set to 90 days and the spatial baseline was set to $\pm 150 \mathrm{~m}$. There are 32 interferograms by using 15 images. The reference image date is $1 / 20 / 17$. 
Table 2. List of interferograms.

\begin{tabular}{|c|c|c|c|c|}
\hline ID & Date 1 & Date 2 & Time baseline (day) & Perpendicular baseline (m) \\
\hline 1 & $11 / 9 / 16$ & $12 / 3 / 16$ & 24 & 53.1178 \\
\hline 2 & $11 / 9 / 16$ & $12 / 27 / 16$ & 48 & 69.425 \\
\hline 3 & $12 / 3 / 16$ & $12 / 27 / 16$ & 24 & 16.3087 \\
\hline 4 & $12 / 3 / 16$ & $1 / 20 / 17$ & 48 & 125.787 \\
\hline 5 & $12 / 27 / 16$ & $1 / 20 / 17$ & 24 & 142.0957 \\
\hline 6 & $12 / 27 / 16$ & $2 / 13 / 17$ & 48 & 25.6572 \\
\hline 7 & $12 / 27 / 16$ & $3 / 15 / 17$ & 78 & 73.382 \\
\hline 8 & $1 / 20 / 17$ & $2 / 13 / 17$ & 24 & 116.4385 \\
\hline 9 & $1 / 20 / 17$ & $2 / 19 / 17$ & 30 & 0.1075 \\
\hline 10 & $1 / 20 / 17$ & $3 / 3 / 17$ & 42 & 57.6997 \\
\hline 11 & $1 / 20 / 17$ & $3 / 15 / 17$ & 54 & 68.7137 \\
\hline 12 & $2 / 13 / 17$ & $2 / 19 / 17$ & 6 & 116.331 \\
\hline 13 & $2 / 19 / 17$ & $3 / 15 / 17$ & 24 & 68.6062 \\
\hline 14 & $2 / 19 / 17$ & $3 / 27 / 17$ & 36 & 97.0211 \\
\hline 15 & $2 / 19 / 17$ & $4 / 8 / 17$ & 48 & 85.7321 \\
\hline 16 & $2 / 19 / 17$ & $4 / 8 / 17$ & 48 & 85.7321 \\
\hline 17 & $3 / 3 / 17$ & $3 / 15 / 17$ & 12 & 126.4134 \\
\hline 18 & $3 / 3 / 17$ & $4 / 8 / 17$ & 36 & 143.5393 \\
\hline 19 & $3 / 15 / 17$ & $3 / 27 / 17$ & 12 & 28.4149 \\
\hline 20 & $3 / 15 / 17$ & $5 / 2 / 17$ & 48 & 6.9285 \\
\hline 21 & $3 / 27 / 17$ & $4 / 8 / 17$ & 12 & 11.289 \\
\hline 22 & $3 / 27 / 17$ & $5 / 14 / 17$ & 48 & 10.8383 \\
\hline 23 & $4 / 8 / 17$ & $5 / 2 / 17$ & 24 & 24.0544 \\
\hline 24 & $4 / 8 / 17$ & $5 / 26 / 17$ & 48 & 65.9036 \\
\hline 25 & $5 / 2 / 17$ & $5 / 14 / 17$ & 12 & 24.5051 \\
\hline 26 & $5 / 2 / 17$ & $5 / 26 / 17$ & 24 & 41.8492 \\
\hline 27 & $5 / 2 / 17$ & $6 / 7 / 17$ & 36 & 50.4958 \\
\hline 28 & $5 / 14 / 17$ & $5 / 26 / 17$ & 12 & 66.3543 \\
\hline 29 & $5 / 14 / 17$ & $6 / 19 / 17$ & 36 & 31.6008 \\
\hline 30 & $5 / 26 / 17$ & $6 / 7 / 17$ & 12 & 92.345 \\
\hline 31 & $5 / 26 / 17$ & $6 / 19 / 17$ & 24 & 34.7535 \\
\hline 32 & $6 / 7 / 17$ & $6 / 19 / 17$ & 12 & 57.5915 \\
\hline
\end{tabular}

\section{LANDSLIDE MONITORING RESULTS AND FORECAST ANALYSIS DISCUSSION}

\subsection{Result of Landslide Monitoring}

The results of the time series for the entire study area calculated using the selected interferograms are shown in Fig. 4. Figure 5 shows the displacement in down-slope direction on the actual map. Then, the average LOS displacements in five selected regions (Fig. 5) in $3 \times 3$ windows (the actual dimensions on the ground are $90 \mathrm{~m} \times 90 \mathrm{~m}$ ) in the Universal Transverse Mercator (UTM) coordinate system in the upper area of the landslide are displayed in Fig. 6.

With regard to the displacement from the near-ridge side to the distant ridge side, the LOS displacement at points A, B, and C are 4.4, 4, and $2.5 \mathrm{~cm}$, from April to mid-June respectively, which is constantly decreasing from northwest to southeast. Meanwhile, the displacement along the eastern side of the ridge (point D) reached a total of $2.7 \mathrm{~cm}$ after April; this displacement was relatively smaller than that along the western part before the landslide occurred. Figure 5 demonstrates that the main deformation area before the landslide can be straightforwardly observed near the western side of the ridge (points $\mathrm{A}$ and $\mathrm{E}$ ).

As shown in Fig. 6, the displacements of the selected five areas are generally consistent. The movement trend of each region is relatively flat from November 2016 to April 

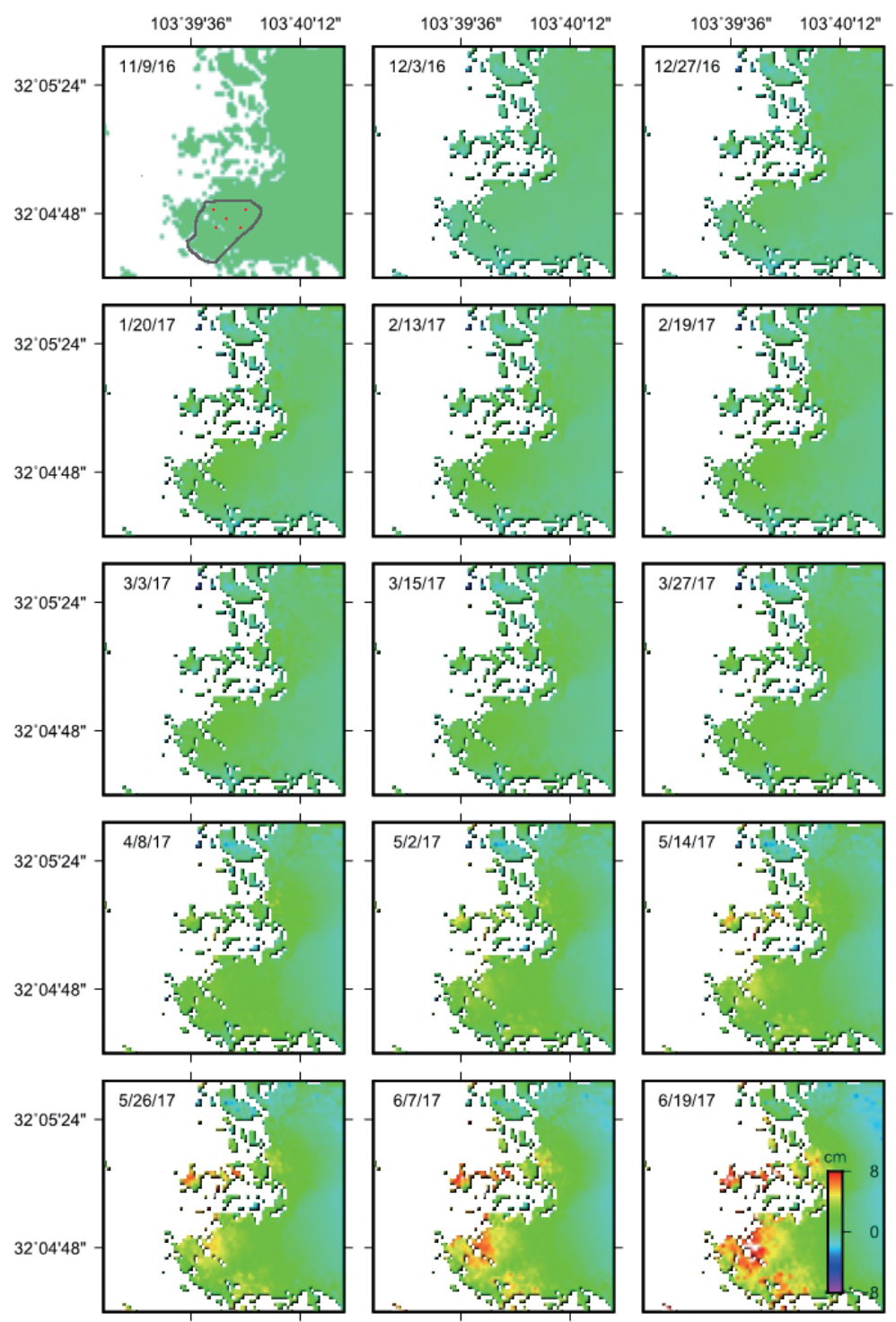

Fig. 4. Deformation maps on LOS direction before the landslide. The landslide source area is circled in the first image and it began to accelerate in April.

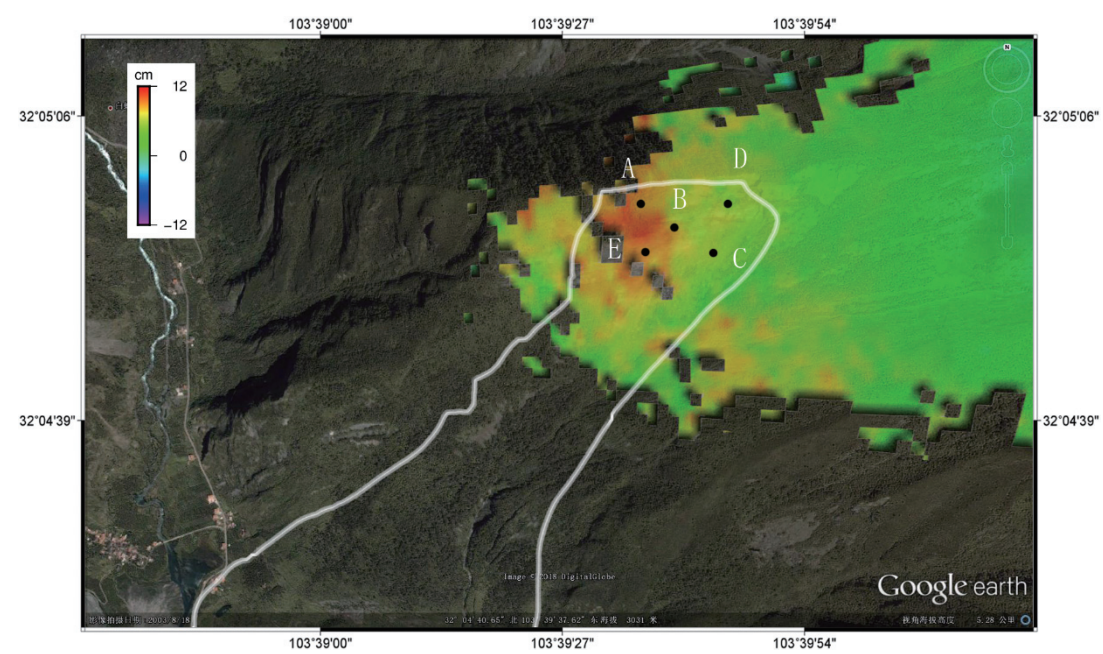

Fig. 5. Displacement on down-slope direction of the landslide. White line is margin of landslide area. Five representative points are selected in figure. One point represents $90 \mathrm{~m} \times 90 \mathrm{~m}$ in the actual dimensions on the ground. 


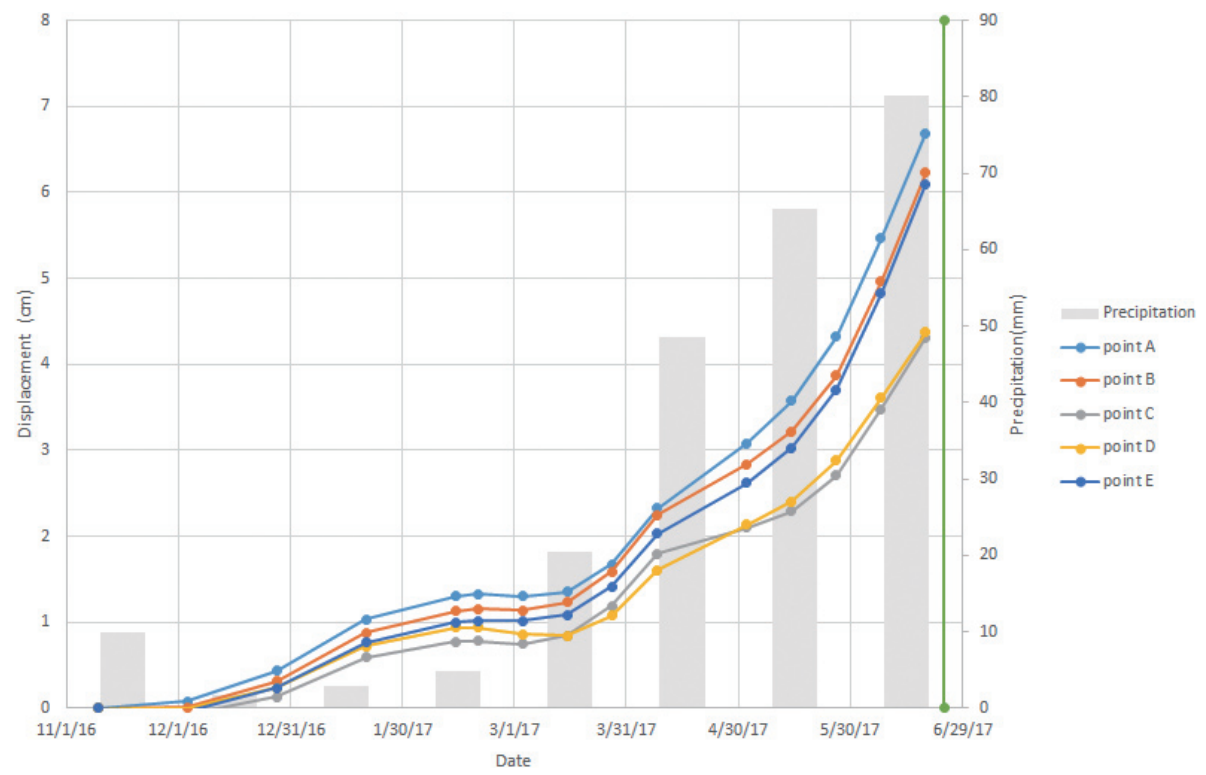

Fig. 6. Movement trend of each point. The green line represents the failure time (June 24). The grey histogram shows mean monthly precipitation recorded by the meteorological station in Mao County between 1981 and 2010 (source: http://data.cma.cn/) (Dong et al. 2018). Rainfall in Mao County is concentrated from May to October.

2017. However, the velocity in each region started to accelerate in April, after which the possibility of slope failure constantly increased until late June. Precipitation is one of the most causes of landslides. Accordingly, based on historical statistics of the monthly average precipitation in Mao County (Fig. 6), the rainfall from April is annually abundant. The onset of displacement in each area before the landslide completely coincides with the monthly precipitation. Therefore, the precipitation is believed to be one of the main causes of this landslide. Between 1 May 2017 and the time of the landslide event, the cumulative rainfall exceeded $200 \mathrm{~mm}$. This value is significantly greater than the average rainfall for the same period throughout the area. Although the amount of rainfall during the days preceding the event was relatively small, a long-duration rainfall event occurred between June 8 and June 15 with a cumulative rainfall amount of $80 \mathrm{~mm}$ and a daily maximum of $25 \mathrm{~mm}$ (Xu et al. 2017).

\subsection{Forecast and Analysis}

The inverse-velocity method developed by Fukuzono in 1985 is an empirical equation prediction method based on the characteristics of accelerated creep, and this approach is closely combined with monitoring curves of landslide displacements (Fukuzono 1985; Intrieri et al. 2018). The inverse-velocity method, which demonstrates good applicability to landslides caused by precipitation (Rose and Hungr 2007; Federico et al. 2012; Carlà et al. 2017) considers the deformation velocity prior to failure as a function variable. The displacement time series (Fig. 6) obtained from InSAR processing clearly illustrate the movement processes of tran- sient creep, steady-state creep and tertiary creep. Therefore, the inverse-velocity method was used to forecast the failure time in this paper.

The landslide source area began to accelerate in April; therefore, the relationship between the inverse velocity and the time was calculated using the nearest possible time, the results of which are shown in Table 3. Figure 7 shows the inverse velocity and time distribution of the five regions selected in the landslide source area. The horizontal axis denotes the time midpoint between two images, and the vertical axis is the inverse velocity $\left(\mathrm{v}^{-1}\right)$. Then, the linear regression is calculated by using the inverse velocity and the times of the last five data points before the landslide from April 8 to June 19. A linear model of $\alpha=2$ is applied to the region with a good linear fit to predict the failure time of the landslide. Among those results, the points within the main deformation area, that is, the area near the western ridge (points $\mathrm{A}, \mathrm{B}$, and $\mathrm{E}$ ), demonstrate a much better fit with an $\mathrm{R}^{2}$ value greater than 0.95 .

According to the results, the inverse-velocity method can be effectively applied to predict the failure time. The estimated failure times calculated through the linear regression of the inverse velocities of the five regions are June 30 , June 23, June 19, July 3, and June 23. However, the estimation result obtained through the linear regression of the points within the area with a good linear fit (i.e., points A, B, and E) is June 25 (Fig. 8), which is only one day apart from the actual failure time. The prediction error is less than the temporal resolution of SAR imagery, which spans from 12 to 24 days. Therefore, the prediction and estimation results are both reliable and effective. 
Table 3. Inverse velocity results $\left(\mathrm{d} \mathrm{mm}^{-1}\right)$.

\begin{tabular}{cccccc}
\hline & A & B & C & D & E \\
\hline $4 / 2 / 17$ & 1.8493 & 1.8210 & 1.9841 & 2.2780 & 1.9481 \\
$4 / 20 / 17$ & 3.1563 & 4.0534 & 7.7539 & 4.5130 & 4.0474 \\
$5 / 8 / 17$ & 2.4449 & 3.1039 & 6.4489 & 4.5381 & 2.9783 \\
$5 / 20 / 17$ & 1.6000 & 1.8555 & 2.9028 & 2.5256 & 1.7624 \\
$6 / 1 / 17$ & 1.0554 & 1.0933 & 1.5442 & 1.6454 & 1.0760 \\
$6 / 13 / 17$ & 0.9780 & 0.9538 & 1.4389 & 1.5649 & 0.9416 \\
\hline
\end{tabular}

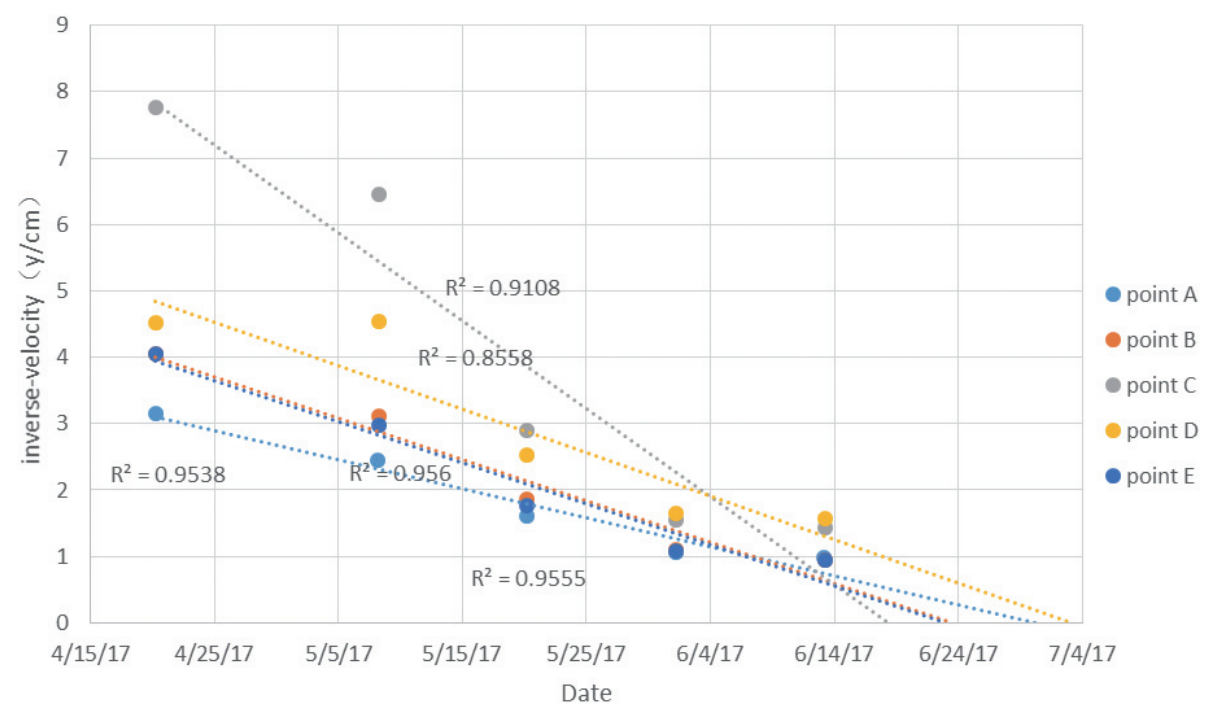

Fig. 7. Linear fitting results of the inverse velocities in each region. The estimated failure times calculated through the linear regression of the inverse velocities of the five regions from A to E are June 30, June 23, June 19, July 3, and June 23.

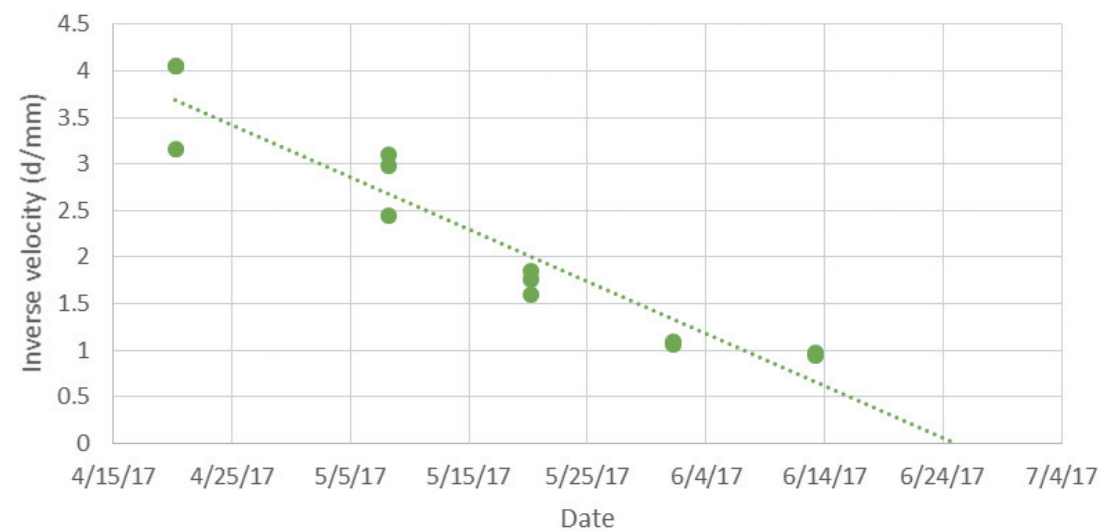

Fig. 8. Linear fitting results of the inverse velocities in three regions (A, B, and E). $\mathrm{R}^{2}=0.9125$, the estimation failure time is June 25 . 
To calculate the landslide failure time, this paper also attempted to apply the theory of the gray Verhulst model (Yin and Yan 1996), which is a statistical model based on the Verhulst model and gray theory that estimates the failure time by calculating the maximum value in the fitting function of the velocity and displacement. The data ranging from April 20 to the time of failure were employed for the calculation using this method. The results for the five above mentioned regions are June 9, June 11, June 10, June 9, and June 11. This method requires that all of the data have the same observation interval, and the fitting function is applicable only to the acceleration stage. Therefore, the selected data are limited; moreover, the fitting model does not coincide with the actual situation, leading to large differences between the predicted times and the actual time. Compared with the inverse-velocity method, this method contains many restrictions and does not work very effectively.

\section{DISSCUSSION}

\subsection{Discussion on Inverse-Velocity Method Based on InSAR Observations}

The results acquired using InSAR encompass observations of the whole surface, and thus, the influence of noise on a single point cannot be ignored. Compared with the results provided by Emanuele Intrieri, this paper selected images from only seven months before the landslide; however, this does not affect the use of the inverse-velocity method to calculate the failure time because the deformation mainly occurred in the months leading up to the landslide. Based on the selected time series, the average displacements of the regions were calculated in windows of $90 \mathrm{~m} \times 90 \mathrm{~m}$ instead of at particular points in the source area to better represent the movement trend of the whole region. In addition, the displacement time series of the five regions were used to forecast the failure time using the inverse-velocity method, and the regression model fitting results for the various regions were compared with each other. It is difficult to employ a strict standard to separate the main deformation areas from other areas based on the results of the displacement time series. Therefore, three representative regions were chosen for the forecasting, following which the predicted results are more reliable those obtained from using a single point.

The Xinmo landslide area started to accelerate in April with only less than three months until the failure; therefore, 3 or 4 values were needed to identify the linear trend in the inverse-velocity regression. Taking the Sentinel-1 satellite as an example, the revisit cycle is commonly 12 days, and thus, identifying a linear trend requires at least 3 images. Accordingly, using only Sentinel-1 satellite SAR images to identify the acceleration trend of a landslide requires data spanning at least a month. Consequently, six images were collected after March but before the landslide failure in this paper, and thus, there are six inverse-velocity values (Table 3 ). The linear trend in the inverse velocity can be confirmed one month before failure, and the acceleration of the deformation can also clearly be observed in the time series. The deformation of a landslide under creeping conditions is steady and slow; as a result, SAR images from a satellite with a short revisit period can be used to observe this deformation process accurately. Time series InSAR technology can utilize a few images in a short period to determine the displacement, and the inversevelocity method can be effectively applied to provide an early warning or even forecast the failure time accurately.

In fact, a decrease in the inverse of the velocity indicates that the velocity of the displacement in the region is increasing. From a model perspective, the inverse velocity will near 0 , at which point the landslide occurs, when the velocity goes to infinity. Thus, the failure time can be estimated or even forecasted. However, when the inverse velocity decreases as the velocity increases, the probability of a landslide will increase. Correspondingly, the potential for landslides to form accidentally and suddenly during the rainy season is very strong. Therefore, monitoring using InSAR data has defects only with regard to the temporal resolution, for which many other monitoring methods such as GPS and ground-based SAR can be used to supplement the data. Therefore, when the inverse velocity of the landslide area is detected below a certain threshold, the instability of an area may be recognized as representative of a high degree of danger even if a landslide event has not yet occurred, and thus, monitoring efforts should be supplemented with other observation methods if conditions permit to reduce or avoid losses.

\subsection{Comparison with Vajont Landslide (Italy)}

Apart from cases triggered by large earthquakes, slope failure is normally preceded by weeks to decades or more of accelerating creep. Failure often appears to occur without warning because of its unnoticed earlier movements. One classic example is the Vajont Landslide occurred on 9 October 1963, which collapsed after nearly 3 years of intermittent, slow deformation, more than 2000 people were killed.

The Vaiont dam constructed between 1957 and 1960, and is located in the narrow and with steep side slopes valley of the Vaiont River. The reservoir level besides the landslide started raising to $700 \mathrm{~m}$ in December 1962, while the displacement rates exceeded $1.5 \mathrm{~cm}^{-1 a y}{ }^{-1}$. When the level was lowered to $650 \mathrm{~m}$ (March 1963), the movements on the slope stopped. The lake level started to be raised again during April 1963. The movements started again after the reservoir level reached $700 \mathrm{~m}$. The velocity of the mass remained low until early September, at a level elevation of $710 \mathrm{~m}$, an immediate increase in the rate of slope movement from 0.5 to $1.0 \mathrm{~cm}$ day $^{-1}$ was observed and continued to increase. The reservoir elevation dropped but the velocity of the slide is out of control and finally crashed (Genevois and Ghirotti 
2005). It is found that the movement rate is related to the water level of the reservoir. Although there is rainfall before the landslide, researchers found that had the reservoir been filled to its design level, the slide might have moved during a period without any significant preceding rainfall (Hendron and Patton 1987).

Traditional controversy focuses on the existence of prehistoric landslide in Vajont to explain the sudden acceleration without enough attention (Kiersch 1964; Caloi 1966). The earlier movements of Vajont Landslide and Xinmo Landslide are both long and slow, but ignored or undetected, which caused heavy loss. Compared to Xinmo Landslide, human factors account for major cause of the failure in Vajont. Raised water pore pressure is crucial to the onset of slope instability (Hendron and Patton 1987). The buoyancy and water thrust due to the raising water level may accelerate the creep process, which may make that the onset of acceleration in Vajont landslide does not show three-stage creep like Xinmo Landslide.

The Vajont landslide was considered to be related to the rising water level in the reservoir while Xinmo landslide was accepted to be triggered by rainfall. However, the trigger cannot account for all the accelerating creep before collapse. Because catastrophic collapses are deep-seated, they normally require the failure of coherent bedrock, and for typical crustal conditions, such failure is invariably brittle. Rock cracking is a mechanism to explain the acceleration of the giant and catastrophic slope failure in Vajont landslide (Kilburn and Petley 2003). Rock cracking is also observed in the source area of Xinmo landslide (Fig. 9), which may be caused by the historical earthquake (Fig. 1). The cracks may support the opinion that the occurrence of the landslide in Mao country is the result of the long-term superposition of active fault and historical earthquakes (Fan et al. 2017; Xu et al. 2017).

\section{CONCLUSION}

Based on Sentinel-1 InSAR image data from November 2016 to June 2017, the SBAS method was used to obtain time series of the pre-slip deformation of the landslide source area in the village of Xinmo, Mao County, Sichuan Province. Then, the landslide failure time was calculated by the inverse-velocity method, the conclusions of which are as follows:

(1) The deformation time series of the source area is coincident with the accelerated creep model. The displacement time series before the landslide clearly show movement processes associated with transient creep, steady-state creep and tertiary creep.

(2) The beginning of accelerated movement in the source area coincides with the regional rainy season, and therefore, precipitation is believed to be the major triggering factor of the landslide.

(3) The time series of the main deformation area can fit a linear model of the inverse velocities better than those of the marginal area, and the forecasted time is closer to the actual failure time. Furthermore, the forecasted time calculated using the time series of three regions is June 25 , which is only one day apart from the actual failure time.

(4) Time series InSAR technology can use a few images acquired over a short period to obtain the displacement time series, and the inverse-velocity method can be applied effectively to provide early warning or even forecast the failure time accurately.

Acknowledgements The research was supported by the State Key Program of National Natural Science of China (No. 41431069), the Foundation for Innovative Research Groups of the National Natural Science Foundation of

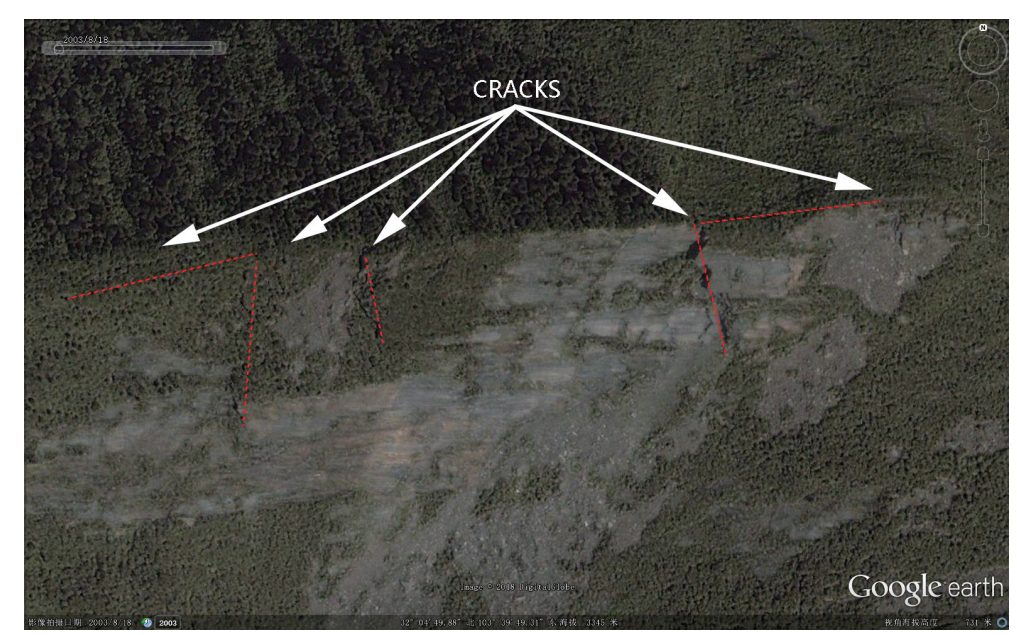

Fig. 9. Images cracks in landslide source area. The Google Earth satellite imagery on 18 August 2003 shows five cracks beside the red lines on the bare rocks in the source area. 
China (No. 41721003), DAAD Thematic Network Project under Grant No. 57173947, National Natural Science Foundation of China (No. 41874011), and the Special Project of Basic Work of Science and Technology (No. 2015FY210400).

\section{REFERENCES}

Berardino, P., G. Fornaro, R. Lanari, and E. Sansosti, 2002: A new algorithm for surface deformation monitoring based on small baseline differential SAR interferograms. IEEE Trans. Geosci. Remote Sensing, 40, 23752383, doi: 10.1109/TGRS.2002.803792. [Link]

Biggs, J., T. Wright, Z. Lu, and B. Parsons, 2007: Multiinterferogram method for measuring interseismic deformation: Denali fault, Alaska. Geophys. J. Int., 170, 1165-1179, doi: 10.1111/j.1365-246X.2007.03415.x. [Link]

Caloi, P., 1966: L'evento del vajont nei suoi aspetti geodinamici. Ann. Geophys., 19, 1-74, doi: 10.4401/ag5037. [Link]

Carlà, T., E. Intrieri, F. Di Traglia, T. Nolesini, G. Gigli, and N. Casagli, 2017: Guidelines on the use of inverse velocity method as a tool for setting alarm thresholds and forecasting landslides and structure collapses. Landslides, 14, 517-534, doi: 10.1007/s10346-016-0731-5. [Link]

Dong, J., L. Zhang, M. Li, Y. Yu, M. Liao, J. Gong, and H. Luo, 2018: Measuring precursory movements of the recent Xinmo landslide in Mao County, China with Sentinel-1 and alos-2 palsar-2 datasets. Landslides, 15, 135-144, doi: 10.1007/s10346-017-0914-8. [Link]

Fan, X., Q. Xu, G. Scaringi, L. Dai, W. Li, X. Dong, X. Zhu, X. Pei, K. Dai, and H. B. Havenith, 2017: Failure mechanism and kinematics of the deadly June 24th 2017 Xinmo landslide, Maoxian, Sichuan, China. Landslides, 14, 2129-2146, doi: 10.1007/s10346-0170907-7. [Link]

Federico, A., M. Popescu, G. Elia, C. Fidelibus, G. Internò, and A. Murianni, 2012: Prediction of time to slope failure: A general framework. Environ. Earth Sci., 66, 245-256, doi: 10.1007/s12665-011-1231-5. [Link]

Ferretti, A., C. Prati, and F. Rocca, 1999: Permanent scatterers in SAR interferometry. IEEE 1999 International Geoscience and Remote Sensing Symposium, IGARSS'99 (Cat. No. 99CH36293), Vol. 3, IEEE, Hamburg, Germany, 1528-1530, doi: 10.1109/IGARSS .1999.772008. [Link]

Fukuzono, T., 1985: A Method to Predict the Time of Slope Failure Caused by Rainfall Using the Inverse Number of Velocity of Surface Displacement. Landslides, 22, doi: 10.3313/jls1964.22.2_8. [Link]

Genevois, R. and M. Ghirotti, 2005: The 1963 Vaiont landslide. Giornale di Geologia Applicata, 1, 41-52, doi:
10.1474/GGA.2005-01.0-05.0005. [Link]

Guidicini, G. and O. Y. Iwasa, 1977: Tentative correlation between rainfall and landslides in a humid tropical environment. Bulletin of the International Association of Engineering Geology, 16, 13-20, doi: 10.1007/ BF02591434. [Link]

Hendron, A. J. and F. D. Patton, 1987: The vaiont slide - a geotechnical analysis based on new geologic observations of the failure surface. Eng. Geol., 24, 475-491, doi: 10.1016/0013-7952(87)90080-9. [Link]

Huang, R. Q., 2007: Large-scale landslides and their sliding mechanisms in China since the 20th century. Chinese Journal of Rock Mechanics and Engineering, 26, 433-454, doi: 10.3321/j.issn:1000-6915.2007.03.001. [Link]

Intrieri, E., F. Raspini, A. Fumagalli, P. Lu, S. Del Conte, P. Farina, J. Allievi, A. Ferretti, and N. Casagli, 2018: The Maoxian landslide as seen from space: detecting precursors of failure with sentinel-1 data. Landslides, 15, 123-133, doi: 10.1007/s10346-017-0915-7. [Link]

Kiersch, G., 1964: Vaiont reservoir disaster. Civil Engineering, ASCE, 34, 32-47.

Kilburn, C. R. J. and D. N. Petley, 2003: Forecasting giant, catastrophic slope collapse: Lessons from vajont, Northern Italy. Geomorphology, 54, 21-32, doi: 10.1016/S0169-555X(03)00052-7. [Link]

Liao, M., J. Tang, T. Wang, T. Balz, and L. Zhang, 2012: Landslide monitoring with high-resolution SAR data in the Three Gorges region. Sci. China Earth Sci., 55, 590-601, doi: 10.1007/s11430-011-4259-1. [Link]

Rose, N. D. and O. Hungr, 2007: Forecasting potential rock slope failure in open pit mines using the inverse-velocity method. Int. J. Rock Mech. Min. Sci., 44, 308-320, doi: 10.1016/j.ijrmms.2006.07.014. [Link]

Shao, C., P. Li, Y. Li, H. Lan, R. Zhou, T. Deng, Z. Yan, L. Yan, and L. Li, 2017: Sliding mechanism of Maoxian landslide and geological condition analysis of formation of post-earthquake landslide. Journal of Chengdu University of Technology (Science \& Technology Edition), 44, 385-402, doi: 10.3969/j.issn.16719727.2017.04.01. [Link]

Tizzani, P., R. Castaldo, G. Solaro, S. Pepe, M. Bonano, F. Casu, M. Manunta, M. Manzo, A. Pepe, S. Samsonov, R. Lanari, and E. Sansosti, 2013: New insights into the 2012 Emilia (Italy) seismic sequence through advanced numerical modeling of ground deformation InSAR measurements. Geophys. Res. Lett., 40, 19711977, doi: 10.1002/grl.50290. [Link]

Xu, Q., W. Li, X. Dong, X. Xiao, X. Fan, and X. Pei, 2017: The Xinmocun landslide on June 24, 2017 in Maoxian, Sichuan: Characteristics and failure mechanism. Chinese Journal of Rock Mechanics and Engineering, 36, 2612-2628, doi: 10.13722/j.cnki.jrme.2017.0855. [Link] 
Yin, K. and T. Yan, 1996: Landslide prediction and relevant models. Chinese Journal of Rock Mechanics and Engineering, 15, 1-8.

Yin, Y., F. Wang, and P. Sun, 2009: Landslide hazards triggered by the 2008 Wenchuan earthquake, Sichuan,
China. Landslides, 6, 139-152, doi: 10.1007/s10346009-0148-5. [Link]

Zeng, Y., 2009: Study on Forecast and Prediction of Large Scale and Sudden Landslide Hazard. Ph.D. Thesis, Chengdu University of Technology. 